\title{
AS RAÍZES DISCURSIVAS DA INTERVENÇÃO MILITAR NA AMAZÔNIA
}

\author{
Filipe Soares ${ }^{1}$
}

\begin{abstract}
RESUMO
O presente artigo pretende estabelecer uma comparação entre os intentos da ditadura militar na Amazônia e os discursos das primeiras fases da colonização na região. Entende-se que parte fundamental do método arqueológico é a construção do arquivo de imagens com que se relaciona determinado saber. Dessa forma, a racionalidade militar que tem a questão amazônica como cerne será investigada à luz dos discursos que se apresentaram ao longo dos primeiros contatos de europeus com a região. $\mathrm{O}$ destaque será dado aos registros dos primeiros conquistadores, bem como aqueles que para a Amazônia se dirigiram no século XVIII, os chamados viajantes naturalistas. De posse de alguns desses relatos históricos, serão feitas algumas comparações com o que postula a ditadura militar ao longo das décadas de 1960 e 1980. O intuito é compor as raízes de derivação do discurso estabelecido pelos militares para amparar suas políticas; apontar suas referências e acusar o diálogo que estabelecem com outras historicidades.
\end{abstract}

Palavras-chave: Amazônia. Ditadura. Arquivo. Discursos.

\begin{abstract}
This article aims to compare the attempts of the military dictatorship in the Amazon and the discourses of the early stages of colonization in the region. It is understood that a fundamental part of the archaeological method is the construction of the image archive with certain knowledge relates. Thus, the military rationality that has the Amazonian issue at its core will be investigated in the light of the discourses presented during the first contacts of Europeans with the region. Emphasis will be given to the records of the first conquerors, as well as those who went to the Amazon in the eighteenth century, the so-called naturalistic travelers. Having some of these historical accounts, some comparisons will be made with what the military dictatorship postulates throughout the 1960s and 1980s. The purpose is to compose the roots of derivation of the discourse established by the military to support their policies; point out their references and accuse the dialogue they establish with other historicities.
\end{abstract}

Key-words: Amazon. Dictatorship. Archive. Discourses.

\section{INTRODUÇÃOO}

Ao longo dos meus estudos sobre as políticas da ditadura militar na Amazônia, pude percorrer alguns documentos oficiais na tentativa de circunscrever a racionalidade utilizada pelo regime durante os anos que interviu na região. O intuito que ainda persigo consiste em montar o quadro discursivo que efetivou e legitimou as ações da ditadura na Amazônia. No exercício da pesquisa e escrita, cheguei à conclusão inicial de que alguns enunciados funcionaram como elementos organizadores deste discurso, são eles: a integração, o nacionalismo, o estigma de espaço vazio, a ideia de fronteira e a necessidade de segurança;

\footnotetext{
${ }^{1}$ Doutorando no Programa de Pós-Graduação em História Social da Amazônia (PPGHIST-UFPA), Professor Substituto da Faculdade de História da UFPA-Campus Bragança. E-mail: menezes.fs@gmail.com.
} 
todos eles orientados e organizados pela obsessão desenvolvimentista que marcou a gestão do período.

Esse foi um primeiro passo conclusivo dos estudos que ainda se encontram em andamento. Como dito, esses estudos fazem parte de uma investigação sistemática nos documentos oficiais que tratam da questão amazônica ao longo dos anos em que os generais se mantiveram como presidentes. Com este artigo, portanto, pretendo avançar com a proposta de entender o saber militar que conformou as políticas na Amazônia. Para este momento, entendi ser necessário enveredar pelo conceito de arquivo, buscando nas primeiras imagens da conquista e da colonização da Amazônia, os referenciais que sobreviveram nos discursos utilizados pelos militares para comporem sua racionalidade.

É chegada a hora, portanto, de estabelecer um sentido de continuidade entre o regime discursivo dos militares sobre a Amazônia e o arquivo de conhecimentos e imagens sobre a região. A tentativa não é aleatória, mas remete à necessidade de demarcar a própria originalidade do conhecimento estabelecido pelos militares quando no momento de prepararem suas intervenções na região. Paradoxalmente, a individualização do recorte operado entre os anos de governo dos generais exige que se estabeleça um domínio de comparação com as épocas anteriores.

O efeito é construir o panorama de uma história geral, onde as críticas dos pressupostos militares se manifestam de maneira a demonstrar como eles não são envoltos por um status de total originalidade histórica. Com isso pretendo revelar como esses discursos constituem um recorte temporal único, mas que, no entanto, estão relacionados com um conjunto de historicidades diversas. Para isso, recorrerei a acontecimentos que remetem ao processo de conquista da região, bem como à fase de elaboração de um conteúdo racional e acumulativo sobre suas riquezas.

É um caminho tortuoso em que desembocarei no domínio de outras instituições e processos econômicos, conformando relações sociais e culturais diferentes das quais encaramos quando na análise do período histórico da ditadura. Fiel ao método arqueológico é que adentrarei agora o terreno de outras formações discursivas, sempre autorizado pelo diálogo com Foucault (ao qual se atribui a criação do método) e com outros teóricos da Amazônia. Ora, "A arqueologia pode assim - e eis um de seus temas principais - constituir a árvore de derivação de um discurso" (FOUCAULT, 2016, p.180) neste caso, veremos como é possível estabelecer as ramificações históricas da discursividade da ditadura. 


\section{OS CONQUISTADORES}

Para dar início a empreitada, iniciarei com a construção dos paralelos entre as formações discursivas que remetem ao período da conquista, em que são apresentados os relatos fundantes da região pela ótica europeia do período. São os "descobridores" que operam esta invenção, inspirados pela construção mítica medieval e renascentista. Em seguida também serão traçados os comparativos com a fase posterior, definida pelos relatos dos viajantes naturalistas que percorreram a região no século XVIII, embalados pelas teorias evolucionistas, positivistas e pelo imperativo do racional. Nesse processo, "a Amazônia é ocupada, primeiramente, pela imaginação fantasiosa do conquistador e, posteriormente, pelo imaginário moderno dos naturalistas" (PIZARRO, 2012, p. 38).

Um primeiro fato construtor do paralelo entre as formações discursivas é o efeito de impacto causado pela descoberta amazônica. Para os militares da ditadura, a tarefa consistia em fazer crer que a exploração da Amazônia se justificava pela sua condição de trampolim: seus usos e exploração facilitariam o salto desenvolvimentista nacional. A Amazônia foi o baluarte do desenvolvimento brasileiro desde o início do regime, e o crescimento econômico passava pela entrada das relações capitalistas na região, trazendo consigo o seu ideal de produtividade. A isto chamei de impacto amazônico na consciência nacional, estimulado pela disseminação dos saberes e dos discursos sobre a região nas representações dos milicos ${ }^{2}$.

Mantendo as especificidades de cada tempo histórico, também é comum encontrarmos na literatura dos primeiros reconhecimentos europeus daquele território, um efeito de impacto diante da imensidão do território, seus rios, habitantes e riquezas naturais. Essa condição é possível de ser observada nas próprias cartas escritas durante as expedições dos conquistadores, dentre as quais se encontram o relato do Frei Gaspar de Carvajal, na viagem capitaneada por Francisco de Orellana; os registros da aventura sanguinolenta da expedição de Lope de Aguirre; e as diversas cartas produzidas ao longo da viagem comandada por Pedro Teixeira ${ }^{3}$.

\footnotetext{
${ }^{2}$ A utilização do conceito de impacto é um dos argumentos que compõe o desfecho da tese a ser defendida no PPHIST-UFPA em fevereiro de 2020. Ela retoma as contribuições de Arthur Cesar Ferreira Reis, importante intelectual da região amazônica que colaborou com as instituições do regime ditatorial.

${ }^{3}$ O Frei dominicano Gaspar de Carvajal é o responsável pelo primeiro documento sobre a penetração do Europeu no rio Amazonas, datado de 1541-1542. Ele é o relator da viagem capitaneada por Francisco de Orellana, que partiu do outro lado dos Andes rumo ao grande rio que corta a Amazônia. Outro relato descobridor, entendido como a contrapartida do que foi registrado durante a viagem de Orellana, é o texto de Cristóbal de Acuña. Em 1641, o jesuíta acompanha a viagem realizada por Pedro Teixeira, percorrendo o mesmo trecho da antiga expedição de Orella, e batiza seu relato de Nuevo descubrimiento del gran río de las amazonas. A viagem de Pedro Teixeira é emblemática, pois sob seu comando a tripulação também percorre, em 1637, o trecho de subida do Rio Amazonas a partir de Belém. Supõe-se que o relato desta primeira viagem, que antecede
} 
Alguns trechos do relato do Frei Gaspar de Carvajal serão aqui apresentados e comentados na sequência, pois atribui-se a ele a autoria do que se convencionou chamar de escritura fundante do território amazônico. Antes disso cabe destacar que o universo comum apresentado por esses cronistas reside na apresentação de um espaço diferente daqueles que se vinham revelando em outros territórios coloniais, como o restante da América Latina, a África e o Oriente. O teor impactante dos relatos é construído pela exuberância das florestas, seus habitantes e principalmente pelo volume dos cursos fluviais pelos quais navegaram os colonizadores. Para Pizarro, naquele momento, "os discursos escritos sobre a Amazônia apresentam, frente aos demais discursos da América Latina, a especificidade do fluvial" (PIZARRO, 2012, p. 18) - não por acaso é que intitula a obra aqui referenciada como Amazônia, as vozes do rio (2012).

Dessa maneira, é o impacto causado pela natureza amazônica que seduz os que a pretendem explorar, seja entre os primeiros conquistadores ou entre os tecnocratas da ditadura. Estes se aproximam quando envoltos pelos mesmos questionamentos de como “dominar, como vencer, como possuir efetivamente um mundo tão estranho?” (REIS, 1972, p. 67). Essas indagações expõem a regularidade com que a região foi tratada pelas investidas que historicamente tentaram garantir um processo de ocupação e transformação pautados numa ideologia civilizatória.

É consenso entre os que abordaram o imaginário da colonização que os europeus recém-chegados à América estavam imbuídos de um sentimento de observação que atestava uma condição paradisíaca dos territórios observáveis. Isto foi analisado por Sérgio Buarque de Holanda como o atrativo exercido pelas "terras incógnitas",

um espaço disposto para o desenvolvimento da fantasia, onde se projetarão tantos os fantasmas cultivados na Idade Média europeia como suas expectativas, as tradições culturais do mundo renascentista, revitalizando o imaginário da Antiguidade grecolatina, a convenção literária dos motivos edênicos, entre outros (PIZARRO, 2012, p. 68).

Composta por este imaginário é que a descrição do mundo amazônico se inicia como uma projeção europeia sobre uma realidade natural e humana. Como exemplos dessa construção mitológica, podemos apontar dois temas em destaque no relato do Frei Gaspar de Carvajal. O primeiro remete às Amazonas e o segundo ao Eldorado. As amazonas, de acordo com o que foi exposto por Carvajal, numa alusão direta ao passado greco-romano, consiste

aquela acompanhada por Cristóbal de Acunã, seja atribuído ao também jesuíta Alonso de Rojas. Entre essas duas expedições, distantes um século uma da outra, também destaquei aquela capitaneada por Lope de Aguirre. Este último toma de assalto o comando de uma viagem capitaneada por Pedro de Urzúa em 1559. 
num grupo de mulheres indígenas e guerreiras que habitavam a região. Essas mulheres se reuniam em povoações onde a presença masculina era somente permitida em períodos específicos para a copulação, no intuito único da reprodução. Nas palavras do Frei:

\begin{abstract}
Aqui viram-se índias com arcos e flechas que faziam tanta guerra quanto os índios ou mais e comandavam e animavam os índios para que pelejassem; e quando queriam batiam com os arcos e flechas aos que fugiam e faziam ofício de capitães ordenando àquela gente que guerreasse, colocando-se na frente e segurando os outros para que estivessem firmes na batalha, a qual travou-se com muito rigor. E sendo este exercício tão estranho às mulheres, como o sexo feminino o requer, e poderá parecer grande novidade ao leitor que vir essa minha relação, digo para meu desencargo que falo do que vi; e o que pudemos entender e se teve por certo é que aquelas mulheres que lá pelejavam como nessas Índias ou partes, corre há muito tempo larga fama, decantada de muitas maneiras da existência dessas belicosas mulheres. As quais nesta província, e não longe dali, têm sua senhoria e mero misto império absoluto senhorio, distante e apartado e sem contato com varões; e essas que vimos era (deveriam ser) umas administradoras e visitadoras do seu estado, que tinham vindo ali para visitar a costa. São altas e de grande porte, desnudas, com uma pequena tanga ("Braga") que somente trazem diante de suas partes mais vergonhosas; mas em (tempo de) paz andam vestidas com mantas e telas de algodão delgadas e mui gentis. (...) E entre nós as chamamos impropriamente de amazonas; porque amazona quer dizer, em língua grega, sem teta; e as que propriamente se chamavam amazonas queimavam-se a teta direita para não serem estorvo ao atirar o arco, como mais longamente o escreve Justino. Mas essas de quem aqui queimam e portanto não podem ser chamadas amazonas, ainda que em outras coisas, como no juntar-se ao homens em certas épocas para seu aumento e (ainda) em outras coisas, parecem imitarem aquelas que os antigos chamaram amazonas (PORRO, 1993, p. $59-61)$.
\end{abstract}

A citação é longa, mas importa à medida que proporciona ao leitor o contato com o relato histórico fundante. Através dele podemos fixar os limites de um imaginário fantasioso, responsável por determinar as bases discursivas com as quais serão construídas o território amazônico. Quero com isso atestar a artificialidade com que são elaborados os mitos recentes do imperativo desenvolvimentista, uma vez que tem como referência os marcos discursivos da fundação do território amazônico aos olhos europeus.

Dessa forma, mesmo que as amazonas se insiram num quadro de revitalização de monstros baseado no arcabouço mitológico europeu, o fato é que elas parecem surpreender Carvajal menos como um elemento fantástico e mais como um prolongamento natural da floresta (PIZARRO, 2012). Seriam elas então uma consequência do enigma e da impenetrabilidade amazônica, região que surpreendia pelo exotismo, somente capaz de abrigar bizarrices, necessitando, portanto, da investida civilizatória europeia. Nesses pressupostos estão o forjamento das necessidades de transformação desse território: retirá-lo de sua condição natural, romper com o exotismo de seus habitantes para pôr em marcha um 
ritmo de conquista, posse e produção - assim como foi colocado, por exemplo, pela ditadura no esforço de transformação do trabalho extrativo e da paisagem florestal amazônica.

Um ponto que merece destaque reside na apelação de Carvajal para garantir a veracidade de seu relato. A expressão "eu vi” guia o leitor para a confiabilidade do que estava sendo dito e faz parte das marcas do gênero literário construído pelos cronistas que fizeram parte dessas expedições. É importante notar que a expressão está ligada a um processo de transformação do regime de verdade pelo qual estava passando a Europa no momento da conquista. O imaginário medieval tinha consolidado uma relação com a verdade segundo a qual esta só poderia ser atingida pela revelação divina. À medida que se avançou na constituição da modernidade, os caminhos para atingir a verdade foram transformados pela importância da experiência e da experimentação, condições fundamentais ao estabelecimento da ciência. A colonização foi o terreno onde foi criada esta nova relação uma vez que os relatos de viagem circulavam na Europa e eram bastante consumidos, tendo em vista as possibilidades abertas com a invenção da imprensa no século XV. Sendo assim, para atestar essa construção verídica fazia-se necessário que o relator tivesse realmente vivido o que falava, participado daquela situação, manifestando sua presença nos acontecimentos que relatava. Daí o sentido de autoridade que carrega a expressão do "eu vi”, e que é utilizada por Carvajal para garantir a credulidade do que postulava.

Mesmo assim, a tarefa de aproximar épocas históricas tão distantes não está completa somente pelo exemplo das Amazonas. Como disse, acredito que elas contribuem mais diretamente com a tentativa de demonstrar como as obsessões europeias na região são fundadas na artificialidade de um esquema fantasioso, o que possivelmente pode ter criado um quadro referencial que tenha sobrevivido com o tempo. Contudo, as aproximações só podem ser realmente assimiladas quando trabalhamos um outro componente desse imaginário. Falo do mito do Eldorado, "responsável pela concretização do desejo de enriquecimento do europeu na América” (PIZARRO, 2012, p. 79).

O mito do Eldorado remete à construção imaginária de que as terras do mundo novo manifestavam um horizonte edênico, assim como alertou Sérgio Buarque. Uma vez que recorriam à aventura nos trópicos, esses viajantes eram estimulados pela existência de um território mítico de riquezas infindáveis. Foi assim que suas narrativas, no momento em que atravessavam a Amazônia, foram construídas com base no esquema de que estavam adentrando um paraíso perdido. O mito consiste na ideia de que quando haviam penetrado o rio Orinoco, os conquistadores espanhóis, "no contato com os índios Achaguas, que cultivavam o Deus Sol, teriam fomentado o imaginário fabuloso sobre as riquezas do lago 
Manoa onde dormiam tesouros infindáveis, palácios dourados e cidades inimagináveis" (CASTRO, 2010, p. 106).

De acordo com Pizarro (2012), o mito fala da existência de um cacique que se banha numa lagoa e após o banho de água, recebe um banho de ouro em pó. Entre as duas versões é comum a percepção de que os lagos e lagoas fomentavam a imaginação de que se tratavam de "espaços rituais". O que se postula, na verdade, é que o mito do Eldorado seria resultado de uma transmissão europeia das imagens de riqueza do Oriente, somadas a percepção ameríndia que associa água à riqueza.

No texto de Carvajal, numa passagem em que ainda se dedica a descrever o império das Amazonas, está apontado que, de acordo com um índio capturado pela expedição, existia no território mítico das amazonas "mui grande riqueza de ouro, porque todas as que são senhoras servem-se dele" (PORRO, 1993, p. 60). Ou seja, a possibilidade de ouro na Amazônia habitava o consciente europeu alimentando seu desejo de conquista e pilhagem. Portanto, podemos definir que o Eldorado não se tratava somente de um lugar geográfico, mas de um sentimento que orientou a investida europeia na região.

Contudo, tendo o Eldorado como horizonte, onde poderíamos localizar uma aproximação possível com a discursividade da ditadura? Bem, segundo Edna Castro, quando falamos de Eldorado estamos diante de um mito fundador da Amazônia. Sua função histórica reside na sua capacidade de "embalar os sonhos de riqueza e de apropriação dos recursos da floresta" (CASTRO, 2010, p. 106). Para ela, o mito do Eldorado foi capaz de atravessar os séculos, constituindo "uma chave do entendimento das sociedades atuais e dos sonhos que mobilizam seus atores" (idem).

Esta reflexão do Eldorado e suas reminiscências no mundo atual praticamente forçou sua entrada no texto que lhes apresento. Digo isto, pois pude constatar algumas manifestações do desejo dos militares na Amazônia, desejos estes que aproximavam os objetivos de enriquecimento na região com o fascínio mitológico de séculos anteriores. Nas palavras do general Albuquerque de Lima, aos militares estava reservada a condição histórica de explorar definitivamente a Amazônia, região "cujos mistérios correm paralelos ao estranho fascínio que suas dimensões de grandeza e seu incalculável potencial de riquezas vem despertando através dos tempos" (ALBUQUERQUE LIMA, 1968, p.50).

Dessa forma, nas palavras do general, o interesse dos militares na região continuou mobilizado pelo fascínio exercido pela grandeza amazônica, local de incalculáveis riquezas. Cabe mais uma vez destacar que as aproximações entre os distintos momentos históricos não são por mim atribuídas, mas são diretamente colocadas pela fala governamental da ditadura. 
Diante disto, existe por parte dos militares, a consciência de que a Amazônia é um território não só de riquezas inesgotáveis, mas de mistérios e fascínios; e assim também foi representada pelos discursos dos europeus nos primeiros anos da conquista.

Essa mediação temporal permite, portanto, a aproximação entre fases discursivas tão distantes uma da outra. Ela aparece quando pretendemos esboçar a árvore genealógica das tentativas de domínio e exploração da região. Mais uma vez, insisto que esta operação é validada pelos próprios interlocutores da ditadura. No mesmo pronunciamento em que profere as palavras anteriormente citadas, o General Albuquerque Lima insiste que a Amazônia,

cujos enigmas tem despertado a imaginação exaltada dos que se vêem envolvidos por esse estranho fascínio, cuja impenetrabilidade se adensa à simples aproximação dos que tem tentado perscrutrar-lhes os mistérios, e cujo potencial de riquezas vem conclamando a todos nós para nos unirmos em sua defesa (ALBUQUERQUE LIMA, 1968, p. 7).

Mistérios, enigmas, fascínios, potencial de riquezas; esse vocabulário utilizado pelo general remete à construção mítica do que representa a região tanto para os militares quanto para os europeus do primeiro contato. Atarefa dos militares é, portanto, uma ação de conquista e esse é o sentido que os aproxima do primeiro momento de colonização. As instituições da ditadura são então orientadas pelo intento de enfrentar os mistérios e os enigmas amazônicos, de posse de uma imaginação exaltada, envolvidos pelo fascínio, mas conscientes do potencial e da riqueza da região. Nas palavras de Edna Castro, "as transformações recentes na Amazônia indicam uma aproximação entre os anseios que impulsionaram a cobiça e a dominação colonial de países europeus na América do Sul" (CASTRO, 2010, p. 106). O mito do Eldorado, atualizado na contemporaneidade, seria responsável pela elaboração de "ideias extravagantes, não menos colonizadoras, sobre as riquezas naturais, sua potencialidade e sua inesgotabilidade” (CASTRO, 2010, p. 106).

Essas "transformações recentes" indicadas por Edna Castro remetem justamente às políticas postas em prática pelos militares. Estas operaram como uma ruptura na história da região e rendem consequências diretas até o presente. $\mathrm{O}$ sentido de continuidade atrelado entre as investidas coloniais e as obras da ditadura, não remetem somente a construção de seus regimes discursivos. O próprio modelo de desenvolvimento imposto na segunda metade do século XX atualiza os pressupostos coloniais, uma vez que funcionou, na prática, de maneira a garantir o saque dos recursos através de um planejamento subsumido aos interesses externos. Numa escala que postula uma análise comprometida com a totalidade, desde os primeiros anos da colonização, temos que o quadro de subsunção colonial na Amazônia não 
se alterou ao longo dos séculos, sendo por outro lado intensificado e atualizado pelo ideário desenvolvimentista contemporâneo.

\section{OS VIAJANTES NATURALISTAS}

A segunda fase discursiva da Amazônia remete às contribuições dos viajantes naturalistas que percorreram a região entre o século XVIII e início do XIX. O paradigma da modernidade, já amadurecido na Europa, foi responsável por operar as rupturas necessárias com a imaginação medieval-renascentista que constituiu o olhar dos primeiros conquistadores. Esses viajantes naturalistas correspondem a um grupo heterogêneo de formação acadêmica diversificada. Entre botânicos, filósofos, matemáticos, astrônomos e mineralogistas, todos contribuíram para a consolidação de um discurso europeu que ganhava cada vez mais força. Sua narrativa característica corresponde ao gênero de uma literatura de sobrevivência, composta por histórias de navegação, "de perigos enfrentados, de maravilhas e curiosidades vistas" (PIZARRO, 2012, p. 98).

Contudo, diferentemente do que se postulava pela narrativa que analisamos anteriormente, esses novos viajantes detinham um compromisso com a razão, uma vez, é claro, que eram justamente os interlocutores da modernidade europeia. Esse compromisso com o racional fez com que seus escritos se voltassem para constituição de um inventário dos produtos amazônicos e das tecnologias de seu povo. Apesar da diversidade de suas formações e da heterogeneidade de seus estudos, parece que, de uma maneira ou de outra, todos os estudiosos concordaram que estavam diante de uma terra rica e apta à exploração e à pilhagem europeia.

À primeira vista este intento já possibilita uma aproximação com o esforço dos militares durante a ditadura militar que assolou o país entre as décadas de 1960 e 1980. À medida que apresentemos as políticas montadas pela racionalidade do regime, perceberemos que parte delas funcionam de maneira a estabelecer um mesmo inventário das riquezas amazônicas, sempre guiados pelo imperativo do racional. Ou seja, para que pudessem explorar as riquezas amazônicas foi preciso um estudo prévio para melhor conhecer suas potencialidades. Dentre essas tentativas de melhor conhecer a região, é possível destacar os planos de investigação das potencialidades energéticas e minerais da Amazônia. Foram os governos militares os responsáveis pela instalação de uma rede hidrelétrica naquelas localidades, assim como foram seus esforços que possibilitaram uma exploração sistemática dos minerais na região. 
A aproximação inicial se dá, portanto, pela condução de uma exploração dita racional, fazendo-se necessário um estudo detalhado das potencialidades do território a que se pretende explorar. Com os viajantes naturalistas, a intenção era conceber novos territórios disponíveis à colonização europeia. No caso da ditadura, a tentativa remete a formular um tipo de exploração compatível com o desenvolvimentismo característico da segunda metade do século XX, ou seja, um desenvolvimento onde a técnica e o industrialismo são preponderantes. Para ambos os casos foi necessário montar um inventário dessas riquezas amazônicas. Descobri-las, registrá-las, catalogá-las... somente assim era possível uma exploração de bases racionais.

No entanto, quando analisamos os discursos, precisamos que essas relações entre as distintas temporalidades sejam postas pela própria fala da ditadura. Ao recuperar o pensamento de Arthur Cesar Ferreiras Reis, intelectual que contribuiu com a racionalidade do regime e ocupou cargos governamentais ao longo da ditadura, foi possível recortar uma reflexão em que o autor se dirige justamente aos intentos dos viajantes naturalistas e suas contribuições às políticas das metrópoles europeias. Vejamos:

À época, os planos de Estado não possuíam as características que possuem hoje as
decisões governamentais. Mesmo assim, não era destituído de fundamento aceitar a
tese de que ocorreu, no tocante aos impérios que se estabeleciam no ultramar dos
povos que se consagravam à façanha de tamanhas perspectivas, a decisão política de
formá-los dentro de certas linhas de ação, que podemos conceber como uma
preliminar de planejamento governamental visando a construção imperial (REIS,
1972, p. 69-70).

A discussão estabelecida na citação é fundamental para darmos continuidade aos paralelos com essa segunda tradição discursiva. Primeiro, temos que garantir as especificidades históricas e a independência dos modelos discursivos construídos pelos viajantes naturalistas e pela mentalidade dos generais-presidentes. Nesse sentido, é impossível discordar do autor quando coloca que os planos das instituições representadas pelos viajantes não podem ser igualados às decisões dos governos no momento em que se estrutura a exploração da Amazônia durante a ditadura.

Por outro lado, Arthur considera como um tipo de fonte de inspiração as tentativas das nações europeias em constituir seus impérios no ultramar. Essas tentativas, por sua vez, constituem os mecanismos utilizados para garantir a exploração da Europa nesses territórios coloniais. São as "linhas de ação" como propõe Arthur Cesar, formadas justamente pela tentativa de organizar um modelo racional de dominação. Este modelo foi concebido pelos viajantes que se dedicavam aos estudos da Amazônia, sua catalogação e registro. 
Para melhor compreender o movimento que aproxima as duas formações discursivas é preciso insistir que estamos diante da monotonia do imperativo do racional. Ou seja, o preliminar esquema de planejamento governamental que vai inspirar os gestores da ditadura e que foi composto na literatura dos viajantes, foi orientado "em torno de se considerar os sistemas classificatórios como essenciais para a ciência compreender a "natureza'" (ALMEIDA, 2008, p. 56). A discussão é longa, mas, neste artigo, podemos em síntese argumentar que a discursividade da ditadura é orientada por um quadro de oposições entre civilização/barbárie e ciência/natureza. Pois essa concepção, sua gênese, encontra-se justamente nos paralelos que os intentos militares estabelecem com a literatura dos viajantes naturalistas do século XVIII. Dessa forma, para melhor entender esse período, mais especificamente as suas contribuições para o estabelecimento do imperativo do racional, inspiração para o planejamento governamental dos militares, faz-se necessário um maior detalhamento dessa segunda fase de discursos sobre a Amazônia, citando agora alguns representantes desse momento histórico.

Primeiro, elegi para a discussão o caso do francês Charles Marie La Condamine. La Condamine foi um astrônomo que percorreu a região amazônica na metade do século XVIII. Ele integra uma expedição da França que em 1735 percorreu o rio Amazonas "com a tarefa de medir o arco do meridiano e determinar o comprimento do pendulo que bate o segundo" (ALMEIDA, 2008, p. 48). O astrônomo também se dedicou a descrever a situação dos povos indígenas e a elaborar um mapa sobre o curso do rio. Mesmo que seu relato muitas vezes adquira um tom de uma narrativa mais literária, constituindo um gênero que relata a experiência de viagem e sobrevivência, é consenso que o francês elaborou um discurso dominado pelo pensamento científico. Seu exemplo é emblemático na constituição da segunda formação discursiva uma vez que se esforça por explicar racionalmente alguns elementos fantasiosos que compuseram a formação discursiva dos conquistadores.

$\mathrm{O}$ viajante escolhe por encarar o mito das Amazonas e o faz de maneira a retirar seu "halo fantasioso" e estabelecer uma imagem de liberação feminina em seu lugar. De acordo com La Condamine, a lenda das amazonas está associada à dificuldade da vida das mulheres na América, onde frequentemente tinham que acompanhar seus maridos na guerra, o que possivelmente poderia ter contribuído para a construção de um lugar imaginário onde essas mulheres se organizariam sem a presença dos homens. Nesse sentido, o relato de La Condamine é em sua essência um relato moderno, pois existe a "procura pela explicação". O mito não deixa de existir, mas são colocadas suas condições de possibilidade e lugar de origem. Para Pizarro, essa narrativa de La Condamine é característica de uma época de 
transição, "em que o aparecimento da racionalidade desloca outras dimensões de restos préracionais" (PIZARRO, 2012, p. 99).

No exemplo de La Condamine podemos então perceber a maneira com que se estrutura o discurso do racional. Este ganha espaço à medida que constrói as rupturas com a fantasia característica da primeira fase, apontando a importância do diálogo com a ciência e com o afastamento dos mitos. Mais do que isso, o sentido de modernidade colocado pela segunda fase encontra-se na sua capacidade de estabelecer um relato utilitarista e instrumental da Amazônia. Eles ganham sua especificidade na forma como se dedicam a construir relatórios que objetivem "implementar de maneira mais imediata sua ação evangelizadora ou seus empreendimentos econômicos nos trópicos" (ALMEIDA, 2008, p. 42).

Outro exemplo de viajante naturalista que deixou um importante legado às interpretações posteriores da Amazônia foi Alexander von Humboldt. A expedição de Humboldt foi patrocinada e autorizada pelo Estado Espanhol. Ele percorreu a América e a região amazônica sob a direção de George Foster, estudioso de mineralogia e história natural. Os trabalhos de Humboldt ficaram muito conhecidos no meio científico europeu. Apesar de ser uma importante referência da época quanto aos estudos da Amazônia, Humboldt não teve sua entrada permitida no Brasil. Naquele momento, Portugal exerceu seus direitos territoriais frente ao interesse de estrangeiros, o que sugere a disputa geopolítica das potências europeias sobre os territórios coloniais e, por conseguinte, sobre a Amazônia.

Humboldt percorreu o canal do Orinoco e passou pelo lago Manoa, catalogando a região através de um rigor científico que o levou a desmitificar a lenda do Eldorado. Essa é uma importante contribuição ao regime da racionalidade que tentava justamente excluir as imaginações fantasiosas a respeito da Amazônia. No entanto, a consciência de que o Eldorado se tratava de um lugar imaginário não fez com que Humboldt também deixasse de lado o sentimento histórico que perpassa o contato estrangeiro com o território Amazônico: o desejo de enriquecimento.

Nesse sentido é que, em um dos seus escritos mais famosos, proclama ser a Amazônia o "celeiro do mundo". Essa imagem constituída pelo viajante influenciou as demais investidas de ocupação e exploração que se sucederam após sua presença na Amazônia. A ideia de "celeiro do mundo" também não passou despercebida pela racionalidade do regime militar 
que, na euforia da Operação Amazônia ${ }^{4}$, relacionou essa intervenção com o que uma vez havia proclamado o naturalista alemão:

A solução do problema amazônico, é imperativo obtê-la a curto prazo. Se desejamos retê-la na área de nossa soberania, urge que aceitemos em definitivo o desafio e que, abandonando as frases de efeito, partamos decididamente para o cumprimento da ciclópica missão, que é lhe dar em concreto a destinação prevista por Humboldt: fazê-la o celeiro do mundo (FOLHA DE SÃO PAULO, 1967) .

Portanto, o regime militar estruturou suas políticas para a região ciente de que era necessário estabelecer um regime de produtividade que garantisse o enriquecimento e a ocupação da área, legitimando dessa forma a soberania brasileira sobre aquele território. Mais uma vez a relação entre as discursividades é garantida pelos próprios porta-vozes do regime. Tanto no período em que Humboldt percorria os rios amazônicos quanto no preparo das políticas dos militares, existia a consciência de que a intervenção na Amazônia era urgente, uma vez que seu quadro natural deveria ser alterado pelas bases racionais, científicas, instrumentais e produtivas. Nesse quadro, a natureza amazônica é entendida como um mundo genesíaco e débil. O futuro só poderia ser alcançado quando estabelecida a dominação da natureza, garantida somente por um sistema de cultivo que viria com a derrubada de suas árvores. É a passagem da natureza para a cultura, base hegemônica do pensamento moderno que perpassa a consciência dos viajantes naturalistas e também compôs a racionalidade dos militares a partir de sua entrada no governo com o golpe de 1964.

Parte dessa concepção sobre a natureza da Amazônia, os elementos humanos da região não foram esquecidos pelos estudos dos viajantes naturalistas. Mas, como disse, apesar da monotonia do discurso do racional, é difícil homogeneizarmos a contribuição desses diferentes estudiosos que chegavam à Amazônia ao longo do século XVIII. Essa diferença fica mais fácil de ser observada quando comparadas as duas tendências de observação que naquele momento compuseram a imagem dos indígenas que habitavam a região. De acordo com Alfredo Wagner, a concepção dos viajantes se dividia entre duas teorias que marcaram o estabelecimento do pensamento moderno: o positivismo e o evolucionismo. De acordo com o autor, para os positivistas do iluminismo

\footnotetext{
${ }^{4}$ Denominação utilizada pelo governo do general Castelo Branco para definir um conjunto de ações direcionados à região, entre elas, a modificação do imposto de renda ao investimento da iniciativa privada em localidades amazônicas.

5 Caderno Especial da Folha de São Paulo que apresenta a divulgação da recém proclamada "Operação Amazônia" - política do governo de Castelo Branco que envolvia benefícios fiscais aos empresários interessados em investir na Amazônia. Tive a oportunidade de me debruçar sobre este material que se encontra nos arquivos do Museu da UFPA.
} 
os 'selvagens' seriam profundamente bons, para os evolucionistas, por sua vez, seriam, sobretudo, 'atrasados', ou seja, 'povos inferiores' vivendo em condições de 'promiscuidade', 'ignorância religiosa', 'amoralidade' e agindo como crianças, com 'raciocínios infantis'. A abordagem evolucionista preconizava ademais a desintegração necessária deste modo de vida para que a sociedade pudesse passar a um estágio mais avançado de desenvolvimento (ALMEIDA, 2008, p. 56).

A perspectiva de Humbold é marcadamente evolucionista, influenciada pela teoria do progresso. Para o estudioso alemão, as formas de vida autóctones representam "o mais baixo grau da civilização humana". Humboldt constrói essa reflexão a partir da constatação de que os gentios formam uma população que dependem de "uma única espécie de palmeira". A fórmula explicativa que guia os teóricos evolucionistas reside na percepção de que os índios viviam numa situação de dependência da natureza, contentando-se somente com aquilo que ela os daria, sem se preocuparem com seu domínio e transformação.

Essa premissa se desdobra discursivamente de acordo com a concepção do determinismo geográfico, onde se percebe nos nativos um indicativo de preguiça e indolência. Por sua vez, essa concepção se arrasta com os séculos e vai compor a ideia de inferioridade racial do norte brasileiro, defendida inclusive por setores de sua elite ainda no século $\mathrm{XX}^{6}$. Ora, é impossível não relacionarmos as teorias evolucionistas com os argumentos do regime militar em proclamar a transformação dos modos de vida extrativistas que caracterizam a economia na Amazônia. Esses argumentos se arrastam na composição institucional que visava a transformação do ambiente amazônico desde a fundação da SPVEA e que vai sobreviver na SUDAM, instituição criada sob o governo dos militares.

\section{RUPTURA E ORIGINALIDADE - NOTAS CONCLUSIVAS}

Contudo, algumas diferenciações podem ser estabelecidas entre as primeiras fases discursivas da Amazônia e a retórica militarista sobre a região. Primeiro, observo que tanto os primeiros colonizadores quanto os naturalistas viajantes (estes mais profundamente) contribuíram para estabelecer o mito clássico do eurocentrismo. Porém, no caso da intervenção da ditadura constata-se uma defesa constante de que a exploração amazônica deveria ser operada não pelas potências europeias, mas pela soberania brasileira na área. Essa constatação desemboca no enunciado nacionalista, parte fundamental da discursividade formada pelos militares para intervir na região.

\footnotetext{
${ }^{6}$ Dentre os representantes do racismo sociológico que condenava "as formas humanas da Amazônia", indico o trabalho de Araújo Lima, em Amazônia, a terra e o homem.
} 
No entanto, a ruptura proposta na fase da ditadura desloca o eixo centro-periferia que se configurou ao longo dos séculos. Antes, a Europa defendia a ideia de que as raças coloniais “simplesmente não tinham o que era necessário para saber o que era bom pra elas". A Europa seria o centro e a população sul-americana residia na periferia. Com o discurso militarista das décadas de 1960 e 1980, a periferia passa a ser restringida pelos modos de vida característicos da Amazônia, onde o centro corresponde às áreas desenvolvidas do país - o Centro-Sul.

Mesmo que a ditadura, no contato com a Amazônia, tivesse a consciência de que seguia o lastro da racionalidade proclamada pelos naturalistas viajantes, os governantes brasileiros do regime também sabiam que teriam de proclamar uma ruptura com esse mito eurocentrista, no qual os únicos capazes de operar uma transformação racional do espaço amazônico seriam os próprios europeus. Essa é uma questão que especifica o saber militar e proclama o nacionalismo brasileiro como um dos grandes enunciados que a compuseram. Para finalizar, portanto, aponto mais um discurso elaborado pelo lugar de fala dos gestores da ditadura, onde são inventariados alguns argumentos que defendem a ruptura do que se estava fazendo naqueles anos com o passado discursivo estabelecido pelo desejo europeu de conquista. Nas palavras de Albuquerque Lima, temos que:

(...) hoje aglutina-se, entretanto, aqui, o interesse de inteligências tocadas por motivações que ultrapassam decerto as antigas aspirações dos que decorreram, em termos de lirismo ou de epopeia, sobre um mundo desconhecido e sobre a força mágica de sua opulência folclórica, de poderoso e impressivo colorido (ALBQUQUERQUE LIMA, 1968, p. 5).

Dessa maneira, o lirismo das narrativas de viagem, suas epopeias e construções folclóricas, apontadas nos relados das primeiras fases discursivas, seriam finalmente superados pela inteligência e racionalismo militar. Os paralelos entre as formações discursivas, indicada nas vozes dos representantes da ditadura, são, portanto, formados não só pelas aproximações, mas também pelos distanciamentos e rupturas com o legado discursivo europeu. Quando se aproximam o fazem para garantir a força e o sentido referencial de seus argumentos, quando se distanciam é para fazer crer que estavam diante de um empreendimento nunca antes visto na região, propondo a singularidade, a ruptura e a originalidade do que estavam a fazer com a Amazônia.

No contato da racionalidade do regime ditatorial com a literatura dos "descobridores" e dos naturalistas viajantes está demarcado o paradoxo que define o estudo das formações discursivas: diferenciações e continuidades; estas só podendo serem construídas quando 
estabelecidas as retóricas dos esquemas interpretativos que tiveram a Amazônia como foco ao longo de sua história.

\section{REFERÊNCIAS}

ALBUQUERQUE LIMA, Afonso Augusto de. A participação do Ministério do Interior no desenvolvimento e na ocupação da Amazônia. Rio de Janeiro: Imprensa do Exército, 1968.

ALMEIDA, Alfredo Wagner Berno. Antropologia dos arquivos da Amazônia. Rio de Janeiro: Casa 8, 2008.

CASTRO, Edna. Políticas de Estado e atores sociais na Amazônia contemporânea. In: BOLLE, Willi; et al. (org.). Amazônia: região universal e teatro do mundo. São Paulo: Globo, 2010.p. 105-122.

FOUCALT, Michel. A Arqueologia do saber. Rio de Janeiro: Forense Universitária, 2016.

PIZARRO, Ana. Amazônia, as vozes do rio. Belo Horizonte: Editora UFMG, 2012.

PORRO, Antônio. As crônicas do Rio Amazonas: tradução, introdução e notas etnohistóricas sobre as antigas populações indígenas da Amazônia. Petrópolis: Vozes, 1993.

REIS, Arthur Cézar Ferreira. O impacto amazônico na civilização brasileira: a Transamazônica e o desafio dos trópicos. Editora Paralelo, 1972.

Recebido em: 28/10/2019

Aprovado em: 30/11/2019 